\title{
Debate on the Multiculturalism: Issues and Particularism
}

\author{
DICKO Abdourahamane \\ Department of Sociology, Wuhan University \\ Wuhan 430072, China \\ E-mail: dabdourahamanedicko772@gmail.com
}

\begin{abstract}
In its appearances and its contemporary manifestation, the challenges provoked by the thrust of cultural identities have up to half a century of history. Since the $60 \mathrm{~s}$, it unveiled the broad social fragility and the problem of coexistence between cultures in democratic countries. This challenge has shacked the dictatorial, the authoritarian regimes, in particular when it alludes to the religious organizations, or national liberation groups. And it taps well our countries, under the shape of religious, nationalist movements, either still fights which recover from what we call indigenism. Faced with this challenge, we cannot formulate summary hypotheses. We are not any more at the beginning phase made by unknowns: we are engaged deeply in conflicts, tensions and transformations which we know already are not ephemeral .It does not obviously mean that their expressions are stabilized, or that their senses are fixed to the long term. To bring knowledge and more clarity on the nature of the problems in cause and on the way they are envisage in the public debate.

We suggest analyzing in what the multiculturalism is a solution of the identical crises. Produce knowledge on the cultural differences, their production, their transformation and their reproduction; examine the problems which they generate in the social life, the meanings which they dress for the interested and for others; report their difficulties and their internal tensions: all is within the competence of the sociological analysis and requires as such specific theoretical and methodological tools. To return our coherent and practical work we are going to support our reflection with a case study, at least comparative between several multiculturalists' models in particular French, American, Canadian and British. This exercise will allow us to kick away hypotheses which will be used as runway to the scientific community and to all society in the grip of the identical crises. However, the elaboration of a theoretical frame of the multiculturalists question stays a preliminary tool. As mentioned theoretical frame elaboration will serve as support of reflection .It will allow us to seize better the notion of the multiculturalism .it will include three main trunk dimensions which are: the Definition of the multiculturalism, the management of the multiculturalism and the identical tensions connected to the vertical and horizontal inheritances. According to Amnesty International multiculturalism is defined as a policy to maintain and to value the various cultures and the communities living within a society. It also implies fighting against the discriminations and promoting the whole and fair individuals participation and the communities of any origins to the social life. This definition brings to light the objectives of an ideal policy of the multiculturalism. We shall also retain of this definition which the multiculturalism can be understood under three approaches: sociological, institutional and ideological. The sociological approach is interested in the ethnic and cultural composition and interactions in the public area. It reports the facts state and the problem aroused by the intercultural relations. The institutional approach is more pragmatic, because it refers to the means of multiculturalism management: in the laws, in the policies, in the regulations, etc. The ideological approach recovers from the philosophic domain. It is the reflection which joins in reaction to the governmental policies about the multiculturalism management.
\end{abstract}

Keywords: Cultural differences, Multiculturalism, Multiculturalism management, Vertical and horizontal inheritances

\section{The Multiculturalism issues}

\subsection{The multiculturalism management}

There are mainly four manners to manage the multiculturalism: the assimilation, the valuation of the differences, the recognition and the multiculturalism. The assimilation bases on the necessity of the rights superiority and the personal freedoms such as conceived by the immigration country. The individuality is the guarantee of equality between the citizens.

For the most moderate, the neutrality of the public sphere is necessary, what means that the government does not interfere in the cultural domain, for more the radicals, the government protects the nation majority culture and 
the citizenship. Contrary to the assimilation, the valuation of the differences promotes the expression of the cultural diversity inside the public area. We try to avoid the hierarchical organization of the cultures. The only condition is that the expression of the difference does not hinder the rights and the liberties such as understands it the State. It establishes the most flexible pole. The recognition is situated between the valuation of the difference and the assimilation. Indeed, we try to establish a just balance between the first two policies. It is interested as much in the tensions aroused by the intercultural relations as in the social and economics conditions of the minorities. Finally, the multiculturalism refers to the model of the cultural mosaic led to the extreme in the sense where every cultural community is connected to the others by the foundation which constitutes all the laws and the regulations promulgated by the government .In this optics, the public area is culturally split up.

\subsection{The identical tensions connected to the vertical and horizontal inheritances}

The multiculturalism management intends to ease the expression of the present identical tensions in the society. These last ones are connected to an imbalance between two types of memberships: vertical and horizontal. The vertical inheritance corresponds to all values, the customs; faiths were connected to the family history. It is about the ancestral culture. The horizontal inheritance corresponds to the events which marked the person identity, and it, since birth. These events are diverse natures and have a different impact. He can involve a meeting, exchanges, a war, a conflict, a school and social education, etc. It is this last one who is the most determining, and becomes more nevertheless; this reality is not reflected in our perception of us. It is not to the vertical inheritance that we refer, but of the other one. We see in this identification a reactionary attitude in front of a situation of exclusion. The multiculturalism as made sociological upset the balance between the vertical and horizontal inheritance, because it multiplies the possibilities of exchanges, enrichment, confrontations, identical conflicts and wounds. It makes a phenomenon which carries as much the germs of the enrichment as the social fragmentation. This social fragmentation is also dependent in the effects of the globalization which widen the radius action of the vertical inheritance.

\section{Presentation of four models of the multiculturalism}

To follow upon the theoretical frame, we propose a study of four models of the multiculturalism which are in crisis

\subsection{French model}

The policy of integration in France is considered very strict. Minority necessarily has to conform to the expectations of the country. It is made possible thanks to the recent hardenings of the selection controls. They impose to the immigrants the idea that France, as immigration country, has to be a choice which supposes an accompaniment of the government, but also efforts on behalf of the individuals. France makes respect its own traditions and its values, while obliging the learning of official language: French. It is the guarantee that the one who comes in France knows and controls the tools of his integration. The first purpose of the French politic is to assimilate the immigrants by making them forget completely their origin. In this way, the government uses the shape of chosen or selective immigration the country chooses his immigrants methodically. In fact, the debate on the illegal immigration ended in a law in November, 2003 and pulled a contraction of the standards relative to the immigration in the broad sense. The law of July 24th, 2006, relative to the immigration and to the integration, marks the passage of a politics of immigration undergone in a selective immigration, because it facilitates the entrance of the immigrants who are going to contribute to the economic development of France. We can see clearly that France also meets itself battling against a problem of racism and xenophobia. The French people also find the too intrusive and threatening Islam. So, the government, by its stiff policies towards the immigrants, strongly contributed to marginalize the immigrants. This situation of exclusion and incomprehension contributes to increase violence in the discriminated districts.

\subsection{The American model}

The policy of American management of the multiculturalism is known under the name of melting pot. It is not however about a very firm policy. Originally, melting pot refers to the perfect assimilation of the foreigner. The immigrant has to conform and become integrated completely into his new country of adoption even if it means forgetting the roots. The pre-war Americanism is a beautiful example of integration of the concept of melting pot by the society. Theodore Roosevelt said moreover: the Americanism is a question of spirit, of conviction and commitment and has nothing to do with the faiths or the place of birth. The real Americanism refers to the incorporation of all the ethnic groups. However, the First World War brings changes as for the meaning of the Americanism. The national integration does not any more correspond to melt the various ethnicities together, but rather to make of the immigrant a diligent, loyal, productive, patriotic citizen, without traditions, without ancestors and without origins to merge better in the American nation. This shape of Americanization deformed 
the first sense of the melting pot so that today, it is not any more represented by the metaphor of the melting pot, but rather by that of the salad bow which means that the various cultures coexist in the same space, but do not mix. This drift is among others explicable by the fact that the real Americanization did not make in-depth and that several xenophobic groups or nativistes required a sorting to avoid the fusions of cultures and claimed restrictive measures in front of the immigration.

The new immigrants, badly integrated within the American nation, were going to become the target of the current xenophobes and nativities, henceforth dominant after the First World War. The assimilation of the foreigners was not any more the first objective of Americanism leaders. It was necessary to them to sort out at first the newcomers to expel those who were not certified loyal. As a consequence, the real Americanization having had no in-depth place, the melting pot has existed never really and left place (square) with the salad bow. We can say that the multiculturalism failed in the United States because the immigrants of different cultures are thrown rejected by the American society.

Although these feel American, the Americans of origin do not so consider them. Consistently, we are observing the fragmentation of the national unit.

\subsection{In Canada}

Canada was the first State to be equipped with a law concerning the multiculturalism, (from 1971). This law had for first objective the construction of the Canadian national unity by valuing the cultural and ethnic diversity, but by limiting all the same application by the Canadian Charter of rights and Liberties. It is the result of the Committee recommendations on the biculturalism of 1965 which proposes the passage of a bicultural policy in a multicultural policy in bilingual frame to answer on one hand the demands of the autochthonous communities and the newcomers, and on the other hand, to avoid the polarization between the Quebeckers and the Canadians except Quebec. By adding the principle of equality, expensive to the law on the multiculturalism, to the

Principle of individuality connected to the Canadian Charter, there would have been itself a cultural space convenient to assimilation.

In quite other a perspective, the criticism of the cultural communities exclusion, a Canadian law on the multiculturalism provoked a fragmentation of the Canadian community according to the principle of the ethno cultural membership, because it revived the intercultural tensions rather than to facilitate the construction of the Canadian nation.

We can regret the association between the principle of equality and the valuation of the difference such as presented in the law, because it asserts that this association allows justifying the exclusion of the ethno cultural groups and blocks the social mobility. The principle of difference proclaimed by the law strengthens the backward-looking attitudes and the lack of communication intercultural, implying so intrinsically a social hierarchy.

\subsection{The British model}

In England, it is the civil society which regulates the expression of the multiculturalism and the integration of the ethno cultural communities, what makes it one of the models the most flexible. The objectives of this policy are fundamentally social. The first objective, the harmonization of the racial relations, is connected to the massive establishment of the newcomers from Asia and from Africa in the London districts. The policy on the multiculturalism aimed, in this order of ideas, to present the members of communities as integral part of a multiracial society basing on values of tolerance. In the first objective, the policy on the multiculturalism planned a series of measures allowing the fight against the racial discrimination and the conservation of the traditional practices in the public area, in particular in the education. It strengthens the ghettoïsation and the auto-segregation and explains a not unimportant proportion of the young Muslims been born in British ground proclaims their religious identity before their civic identity. We realize the profound incapacity of communication and incomprehension which this policy cultivated.

\section{Differences and resemblances between the four models}

First, France approaches the assimilation and the pole of cultural luggage of the immigration country. France, by its policy of assimilation, is rather severe and more conservative. The immigrant has to conform completely to the values of the republic and merge in a mould by forgetting all, and where he comes from .The French model is placed below, to the left of the plan, because of our four examples, it is about a model which completely disregards the cultural luggage of the native country of the immigrant. There are resemblances between the French and American management policies of the multiculturalism. That is why we placed the American model in the same dial as France, but closer of the center because it is suppler. Indeed, the first definition of the melting 
pot facilitates the assimilation of the immigrant on one hand by allowing this one to participate in the construction of the American identity on the other hand by complying with American way of life.

A change took place after the First World War with the succession of the salad bow model. This second definition refers to the hegemonic character of the United States which sees to it all which is exotic seen revised and incorporated into the American culture. The cultural constituent so loses its original sense. It is the Americanization such as we know it today, but it does not have any more for objective to transform the culture, because he acts as a balm in the mould proposed to the members of the cultural communities. The immigrant has to cut with his roots to become a real American; however he does not undergo the rigidity of the French-style policies, because the government legislates little in expression of the difference in the public area. Contrary to these visions rather assimilative live the model of Great Britain which approaches most the valuation pole and the differences.

It is very supple in the sense which he allows the newcomers to protect their lifestyle, and it, practically without limit. It would explain the location to the other extremity of our plan near the pole of the cultural luggage of the native town. The Canadian model meets itself in the same dial as that of Britain, but more in the center quite as the American model with regard to France. The Canadian model is stricter than the British model, because it puts limits in the demands of the cultural communities in the public area.

This model approaches the American model, because it allows the diverse cultural communities to participate in the construction of the Canadian identity. However, the Canadian model proposes a politics which values the equality in the differences contrary to the American model which values the standardization. What differentiates the French model of the American model, quite as what differentiates the British model of the Canadian model; is the State has no same degree of acceptance in front of the culture modification in the time. Their inclination to regulate the intercultural relations in the public area is however similar. In other words, the French model is for the American model that the British model is for the Canadian model. In the American and French case of the models, although they are situated both in the pole of the assimilation, they do not show officially the same objectives. Although the French model and the British model establish two radical models, they differ in their inclination to regulate the intercultural relations in the public place, that is the French model puts the intercultural relations as an obstacle in the national identity, because it would encourage the balkanization of the society, while the British model encourages the cultural differences by lauding the equality between the cultures. The American and Canadian models establish the most moderate and the most flexible models. However, they differ in their inclination to regulate the intercultural relations in the public place. The American model proposes a mould to which it is necessary to conform while the Canadian model proposes the cultural mosaic.

\section{Hypothesis proposition}

To answer this questioning, we integrated into our initiative of the concepts explained previously, more particularly, the concepts of assimilation and valuation of the differences as well as the vertical and horizontal inheritance. We put them in relation in a plan constitute by two perpendicular axes. The vertical axes represent the concept of vertical inheritance. Both extremities of this axes set the country cultural luggage to the native country or ancestral culture for the minority cultural communities members. The horizontal inheritance sees the individuals of the same society meet themselves pulled somewhere between both extremities of the axes, but rarely meet themselves in extremes.

The policies of multiculturalism management partially for objective watching the identical tightness is regulated and enriching socially, what is not at present the case. These governmental politics policies are situated on the horizontal axis where oppose the pole of the assimilation and the differences valuation. In the reality, streams of tensions are applied on these two axes. According to us, to reach the model of multiculturalism management would be necessary invert the streams of tensions and arrive at streams of communication in the public area. So, we suppose there is an intimate link between the identical mechanism of the citizens and the difference management. The individual identity builds up itself in a context of opening, equity and respect, more various members of the same society will feel capable of becoming integrated into it and of becoming identified with it and, finally, the more State will be capable of collecting her population around a common project. We also suppose that the communication is preliminary in the elaboration of a project of society, so this last one is long-lasting. According to us, the government cannot propose a project of society and a political frame if it is not preceded by a policy of cultural diversity management which allows the transformation of the common public culture and it, in a democratic way. Indeed, the identical character of a person or a group of persons is strictly connected to the perception which people, or society generally, have of them, where from the essential character of the recognition of the other one. By denying the cultural identity of a group or simply by denigrating it, we come there to affect the group which defines itself by the glance which the society concerns him. The 
recognition is not simply a politeness which we make to people: it is a vital human need. The non-recognition can entail the contempt, the hatred or the denial of one whereas the recognition dismisses to the dignity principle: each in right for the dignity and, for the recognition. It is possible only in a democratic and equalitarian context. This statement supposes that we are inevitably influenced by the culture in which we evolved and that it is what defines our cultural identity and, consequently, ourselves.

So, if our cultural identity is not recognized, we feel rejected. This expressed installation as well as the recognition forces the identity, because to grant the recognition for one person to the identity difference, it is to grant to this person to be what it is. The policy of the recognition expresses a desire to be respected and not a desire of condescension, which is of the other thing than the false depreciating respect. It is a question of recognizing, all so much whom we are, the value equals various cultures, that is not only to let them survive, but still to recognize their merit. However, this policy will be possible only if we agree to widen our horizon, to change the vocabulary of comparison, to open in the comparative cultural study and to include what is different is not inevitably less good or bad. These changes would allow deviating from the value judgment to give way to the recognition of the differences.

\section{Conclusion}

So, not only our societies receive and reproduce differences, but they invent it, including under the seal of the tradition. Each of us, in the most immediate circle of acquaintances, is confronted with the raid of new identities, even with conversions; each of us observes the development of cultural movements. Some leave indifferent, the others arouse the most diverse feelings, of understanding and sympathy or, on the contrary, fear, aversion and discharge. Some day, each of us can also notice that his own experience of a cultural sense of identity, including the most stable seemingly, is not inevitably definitive, that personal changes are always possible, susceptible to lead us up to the pure and simple renunciation of an identity, to adopt if necessary a piece of news.

And each of us proceeds to choices relative to the present and in the future, but also in the past: more and more, we make our report; we fall towards the future by claiming our registration in a history which we make ours.

We live in societies of reception, but also individual and collective production of the differences, and we know it. In such societies, the political mechanisms of treatment of the difference become inescapable, as we name them multicultura-lists or as we indicate them otherwise. To face at once considerable and changeable phenomena, operating within the whole society, beyond and on this side, be satisfied with abstract and automatic rules seems very insufficient, otherwise dangerous: The push of the cultural differences always calls more democracy, so as to assure individually the political examination of the demands which they advance, and who are complex all the more as they have generally strong social involvements. This treatment should be applied closer, scale local as global ladder, via the action of the big international organizations in particular.

In front of problems raised by such or such cultural difference, the political action needs to join a vision of set, a frame marked out by general orientations, principles of Justice and democratic values. But it is also necessary to her to take into account expectations and demands which do not limit themselves to the only carrier group of the considered difference. This situation confers a major role to all those who exercise an influence on the opinion, whether it is in the plan of the principles and the values or about a particular difference.

We know that the identities do not constitute one given unchanging, capable only of reproducing or of disappearing; we know that they are, at least partially, what our societies make. It means that there is place, on the subject, for reflexivity, a capacity to consider them in the second degree, as the fruit of the work of the society on itself, and not only as so many challenges or threats. It means, in other words, that next to the journalism and to the information, a necessary place returns to the social sciences, including if it is a question of pressing on the opinion and on the representations which it adopts.

\section{References}

American Psychological Association. (2010). Publication manual of the American Psychological Association (6th ed.). Washington, DC: Author.

Andrew, W. (1992). Economic Reform and Social Change in China. New York: Routledge.

Anthony, S. (1981). The Ethnical Revival in the Modem World. Cambridge University Press.

Auerbach, SU. (1994). Encyclopedia of multiculturalism, New York: Marshall Cavendish.

Bandura, A. (1986). Social foundations of thought and action: A social cognitive theory. Englewood Cliffs, NJ: Prentice Hall.

Barber, E. J. W. (1999). The Mummies of Urumchi. New York: W.W. Norton \& Company.

Bartol'D, V. V. (1956). Four Studies on the History of Central Asia. Leiden, E.J. Brill. 
Bernstein, RI. (1994). Dictatorship of virtue: Multiculturalism and the Battle for America's Futur. New York: A. A. Knopf.

Castets, R. (2003). The Uyghurs in Xinjiang. The Malaise Grows in China. Perspectives, n.49, pp. 34-48.

Castets, R. (2004). Nationalisme, islam et opposition politique chez les Oü̈gours du Xinjiang. In Les Études du CERI, octobre, n.110, 45 pages.

Cheng, Li. (1997). Rediscovering China, Dynamics and Dilemmas of Reform. Lanham: Rowman and Littlefield.

Christoffersen, G. (1993). Xinjiang and the great Islamic circle: the impact of transnational forces on Chinese regional economic planning. China Quarterly no.133 (March):130-151.

Daniel, B. (1969). Vers la société post-industrielle. Paris, Robert Laffont,; Main.

Dru, G. (1996). Muslim Chinese, Ethnic Nationalism in the People's Republic. Cambridge: Harvard.

Feng, J. (1996). Xinjiang: a big family of unity and progress. Beijing Review, 39. 3 (Jan):15-21.

Franklin E. (1957). Black Bourgeoisie. New York, the Free Press.

Friesen, JH. (1993). When cultures clash: case studies in multiculturalism. Calgary: Detselig Entreprises.

GATES \& Louis, H. (1992). Loose canons: Notes on the Culture Wars. New York: Oxford University Press.

Gina, Ph. (1999). From Black to African American. A New Social Representation. Wesport et Londres, Praeger.

Gladney \& Dru, C. (1991). Muslim Chinese: ethnic nationalism in the People's Republic. Cambridge, Mass.: Council on East Asian Studies, Harvard University.

Gladney \& Dru, C. (1994). Ethnic identity in China: the new politics of difference. In Joseph, William A., ed. China briefing. Boulder, Colo.; Oxford, Eng: West view Press, 171-192.

Glazer, N. (1998). We are All Multiculturalists Now. Cambridge, MA: Harvard U. Press.

LECA, J. (1991). Individualisme et citoyenneté. In Sur l'individualisme. Théories et méthodes. BIRBAUM, Pierre et Jean LECA, p.159-209. Paris: Presses de la FNSP.

Li, S., \& Anwar, A. (1995). Summary of research on the racial and ethnic origins of China's Xinjiang Uighur ethnic group. In: Sautman, Barry, ed. Racial identities in East Asia (Tung Ya chung tsu ren tung). Hong Kong: Division of Social Science, Hong Kong University of Science and Technology, 601-636.

LIND, M. (1996). The Next American Nation: The New Nationalism and the Fouth American Revolution. New York: Free Press.

Loïc, W. (1989). The Cost of Racial and Class Exclusion in the Inner City. The Annals of the American Academy of Political and Social Science.

MARSHALL, R., \& Thomas, H. (1965). Class, Citizenship and Social Development. New York: Anchor Books. Martin Barker. (2006). the New Racism, Londres, Junction Books.

Max, W. (1959). Le Savant et le Politique. Paris, Plon.

Michael, S. (1982). Liberalism and the Limits of Justice. Cambridge University Press.

Norbert, E. (1975). La Civilisation des mours, Paris, Calmann-Lévy, et La Dynamique de l'Occident. Paris, Calmann-Lévy.

Paul, G. (1993). The Black Atlantic. Modernity and Double Consciousness. Cambridge (Mass), Harvard University Press.

Satzewich, H., \& Victor, N. (1992). Deconstructing a nation. Halifax: Fernwood.

SEMPPRINI, A. (1997). Le multiculturalisme. Paris Presses Universitaires de France.

Stevan, H. (1995). Cultural Encounters on China's Ethnic Frontiers. Seattle: U. of Washington Press.

Takaki, D. \& Ronald, T. (1993). A different Mirror. A History of Multicultural America. Boston: Little Brown.

Thomas, H. (1989). China and its National Minorities: Autonomy or Assimilation. NY: Sharpe.

Touraine. (1969). La Société post-industrielle. Paris, Denoël.

Wang, J. (1998). Sufi Orders in the History of Xinjiang. Project work at the Truman Institute of Advancement for Peace. Hebrew University of Jerusalem.

Waters, B. \& Mary, C. (1990). Ethnics Options: Choosing Identities in America. Berkeley University of California Press.

William, W. (1987). The Truly Disavantaged: The Inner City, The Underclass and Public Policy. Chicago, Chicago University Press. 